\title{
Artificial intelligence and machine learning research: towards digital transformation at a global scale
}

\author{
Akila Sarirete $^{1} \cdot$ Zain Balfagih $^{1} \cdot$ Tayeb Brahimi $^{1} \cdot$ Miltiadis D. Lytras $^{1,2} \cdot$ Anna Visvizi $^{3,4}$
}

Published online: 17 April 2021

(c) The Author(s), under exclusive licence to Springer-Verlag GmbH Germany, part of Springer Nature 2021

Artificial intelligence (AI) is reshaping how we live, learn, and work. Until recently, AI used to be a fanciful concept, more closely associated with science fiction rather than with anything else. However, driven by unprecedented advances in sophisticated information and communication technology (ICT), AI today is synonymous technological progress already attained and the one yet to come in all spheres of our lives (Chui et al. 2018; Lytras et al. 2018, 2019).

Considering that Machine Learning (ML) and AI are apt to reach unforeseen levels of accuracy and efficiency, this special issue sought to promote research on AI and ML seen as functions of data-driven innovation and digital transformation. The combination of expanding ICT-driven capabilities and capacities identifiable across our socio-economic systems along with growing consumer expectations vis-a-vis technology and its value-added for our societies, requires multidisciplinary research and research agenda on AI and ML (Lytras et al. 2021; Visvizi et al. 2020; Chui et al. 2020).

Akila Sarirete

asarirete@effatuniversity.edu.sa

Zain Balfagih

zbalfagih@effatuniversity.edu.sa

Tayeb Brahimi

tbrahimi@effatuniversity.edu.sa

Miltiadis D. Lytras

mlytras@acg.edu

Anna Visvizi

avisvizi@acg.edu

1 Effat College of Engineering, Effat Energy and Technology Research Center, Effat University, P.O. Box 34689, Jeddah, Saudi Arabia

2 King Abdulaziz University, Jeddah 21589, Saudi Arabia

3 Effat College of Business, Effat University, P.O. Box 34689, Jeddah, Saudi Arabia

4 Institute of International Studies (ISM), SGH Warsaw School of Economics, Aleja Niepodległości 162, 02-554 Warsaw, Poland
Such a research agenda should oscilate around the following five defining issues (Fig. 1):

(1) Integration of diverse data-warehouses to unified ecosystems of AI and ML value-based services

(2) Deployment of robust AI and ML processing capabilities for enhanced decision making and generation of value our of data.

(3) Design of innovative novel AI and ML applications for predictive and analytical capabilities

(4) Design of sophisticated AI and ML-enabled intelligence components with critical social impact

(5) Promotion of the Digital Transformation in all the aspects of human activity including business, healthcare, government, commerce, social intelligence etc.

Such development will also have a critical impact on government, policies, regulations and initiatives aiming to interpret the value of the AI-driven digital transformation to the sustainable economic development of our planet. Additionally the disruptive character of AI and ML technology and research will required further research on business models and management of innovation capabilities.

This special issue is based on submissions invited from the 17th Annual Learning and Technology Conference 2019 that was held at Effat University and open call jointly. Several very good submissions were received. All of them were subjected a rigorous peer review process specific to the Ambient Intelligence and Humanized Computing Journal.

A variety of innovative topics are included in the agenda of the published papers in this special issue including topics such as:

- Stock market Prediction using Machine learning

- Detection of Apple Diseases and Pests based on MultiModel LSTM-based Convolutional Neural Networks

- ML for Searching 
Fig. 1 An AI-Driven Digital Transformation in all aspects of human activity/ Source: The Authors
1.Level 1: Integration of diverse datawarehouses to unified ecosystems of Al and $M L$ value-based services
1.Level 2: Deployment of robust Al and ML processing capabilities for enhanced decision making and generation of value our of data.

\section{Level 3: Design of innovative novel Al
and ML applications for predictive and \\ 1.Level 3: Design of innovative novel Al
and $M L$ applications for predictive and analytical capabilities}

Level 5: Al-driven

Digital Transformation

in all the aspects of

human activity
1.Level 4: Design of sophisticated AI and $\mathrm{ML}$-enabled intelligence components with critical social impact
- Machine Learning for Learning Automata

- Entity recognition \& Relation Extraction

- Intelligent Surveillance Systems

- Activity Recognition and K-Means Clustering

- Distributed Mobility Management

- Review Rating Prediction with Deep Learning

- Cybersecurity: Botnet detection with Deep learning

- Self-Training methods

- Neuro-Fuzzy Inference systems

- Fuzzy Controllers

- Monarch Butterfly Optimized Control with Robustness Analysis

- GMM methods for speaker age and gender classification

- Regression methods for Permeability Prediction of Petroleum Reservoirs

- Surface EMG Signal Classification

- Pattern Mining

- Human Activity Recognition in Smart Environments

- Teaching-Learning based Optimization Algorithm

- Big Data Analytics

- Diagnosis based on Event-Driven Processing and Machine Learning for Mobile Healthcare

Over a decade ago, Effat University envisioned a timely platform that brings together educators, researchers and tech enthusiasts under one roof and functions as a fount for creativity and innovation. It was a dream that such platform bridges the existing gap and becomes a leading hub for innovators across disciplines to share their knowledge and exchange novel ideas. It was in 2003 that this dream was realized and the first Learning \& Technology Conference was held. Up until today, the conference has covered a variety of cutting-edge themes such as Digital Literacy, Cyber
Citizenship, Edutainment, Massive Open Online Courses, and many, many others. The conference has also attracted key, prominent figures in the fields of sciences and technology such as Farouq El Baz from NASA, Queen Rania AlAbdullah of Jordan, and many others who addressed large, eager-to-learn audiences and inspired many with unique stories.

While emerging innovations, such as Artificial Intelligence technologies, are seen today as promising instruments that could pave our way to the future, these were also the focal points around which fruitful discussions have always taken place here at the L\&T. The (AI) was selected for this conference due to its great impact. The Saudi government realized this impact of $\mathrm{AI}$ and already started actual steps to invest in AI. It is stated in the Kingdome Vision 2030: "In technology, we will increase our investments in, and lead, the digital economy." Dr. Ahmed Al Theneyan, Deputy Minister of Technology, Industry and Digital Capabilities, stated that: "The Government has invested around USD 3 billion in building the infrastructure so that the country is AI-ready and can become a leader in AI use." Vision 2030 programs also promote innovation in technologies. Another great step that our country made is establishing NEOM city (the model smart city).

Effat University realized this ambition and started working to make it a reality by offering academic programs that support the different sectors needed in such projects. For example, the master program in Energy Engineering was launched four years ago to support the energy sector. Also, the bachelor program of Computer Science has tracks in Artificial Intelligence and Cyber Security which was launched in Fall 2020 semester. Additionally, Energy $\&$ Technology and Smart Building Research Centers were 
established to support innovation in the technology and energy sectors. In general, Effat University works effectively in supporting the KSA to achieve its vision in this time of national transformation by graduating skilled citizen in different fields of technology.

The guest editors would like to take this opportunity to thank all the authors for the efforts they put in the preparation of their manuscripts and for their valuable contributions. We wish to express our deepest gratitude to the referees, who provided instrumental and constructive feedback to the authors. We also extend our sincere thanks and appreciation for the organizing team under the leadership of the Chair of L\&T 2019 Conference Steering Committee, Dr. Haifa Jamal Al-Lail, University President, for her support and dedication.

Our sincere thanks go to the Editor-in-Chief for his kind help and support.

\section{References}

Chui KT, Lytras MD, Visvizi A (2018) Energy sustainability in smart cities: artificial intelligence, smart monitoring, and optimization of energy consumption. Energies 11(11):2869
Chui KT, Fung DCL, Lytras MD, Lam TM (2020) Predicting atrisk university students in a virtual learning environment via a machine learning algorithm. Comput Human Behav 107:105584

Lytras MD, Visvizi A, Daniela L, Sarirete A, De Pablos PO (2018) Social networks research for sustainable smart education. Sustainability 10(9):2974

Lytras MD, Visvizi A, Sarirete A (2019) Clustering smart city services: perceptions, expectations, responses. Sustainability 11(6):1669

Lytras MD, Visvizi A, Chopdar PK, Sarirete A, Alhalabi W (2021) Information management in smart cities: turning end users' views into multi-item scale development, validation, and policy-making recommendations. Int J Inf Manag 56:102146

Visvizi A, Jussila J, Lytras MD, Ijäs M (2020) Tweeting and mining OECD-related microcontent in the post-truth era: A cloud-based app. Comput Human Behav 107:105958

Publisher's Note Springer Nature remains neutral with regard to jurisdictional claims in published maps and institutional affiliations. 